\title{
Prevalence of post-traumatic stress disorder, acute stress disorder and depression following violence related injury treated at the emergency department: a systematic review
}

\author{
Robbin H. Ophuis ${ }^{*}$ (D), Branko F. Olij, Suzanne Polinder and Juanita A. Haagsma
}

\begin{abstract}
Background: In order to gain insight into the health impact of violence related injury, the psychological consequences should be taken into account. There has been uncertainty regarding the prevalence of posttraumatic stress disorder (PTSD), acute stress disorder (ASD), and depression among patients with violence related injury. An overview of prevalence rates may inform our understanding of both prognosis and recovery for these patients. Therefore, we aim to provide an overview of the published literature reporting the prevalence rates and trajectories of PTSD, ASD, and depression following violence related injury, and to assess the quality of the studies included.

Methods: A systematic review was conducted in order to provide an overview of the published literature reporting the prevalence of PTSD, ASD and depression following violence related injury treated at the emergency department or hospital. The EMBASE, MEDLINE, Cochrane Central, PubMed, and PsycINFO databases were searched systematically. The quality of the included studies was assessed.

Results: We included sixteen studies reporting the prevalence rates of PTSD, ASD, or depression. Clear prevalence trajectories could not be identified because the range of prevalence rates was diverse at each time point. Heterogeneity resulting from the use of different diagnostic instruments limited comparability. The included studies were susceptible to bias due to low response rates and loss to follow-up.

Conclusions: The differences in diagnostic instruments limited comparability of the prevalence rates. Therefore, clear prevalence trajectories could not be identified. Study participation and loss to follow-up require more attention in future studies. Uniformity in diagnostic procedures is needed in order to draw general conclusions on the prevalence of PTSD, ASD, and depression following violence related injury.
\end{abstract}

Keywords: Depression, Post-traumatic stress disorder, Trauma, Violence, Injury, Emergency department, Prevalence

\footnotetext{
* Correspondence: r.ophuis@erasmusmc.nl

Department of Public Health, Erasmus University Medical Center, PO Box 2040, 3000, CA, Rotterdam, The Netherlands
}

(c) The Author(s). 2018 Open Access This article is distributed under the terms of the Creative Commons Attribution 4.0 International License (http://creativecommons.org/licenses/by/4.0/), which permits unrestricted use, distribution, and reproduction in any medium, provided you give appropriate credit to the original author(s) and the source, provide a link to the Creative Commons license, and indicate if changes were made. The Creative Commons Public Domain Dedication waiver (http://creativecommons.org/publicdomain/zero/1.0/) applies to the data made available in this article, unless otherwise stated. 


\section{Background}

More than 1.5 million people worldwide die from violence related injury every year, and even more people suffer from non-fatal injury caused by violence [1]. Approximately 1.4 million non-fatal violence related injuries are treated annually in hospital emergency departments (ED) in the US [2]. In Western Europe, 670,000 violence related injuries require medical treatment each year [3]. According to the diagnostic and statistical manual for mental disorders (DSM), exposure to serious injury is an example of a traumatic event [4]. Longitudinal studies of responses to traumatic events show that mental disorders such as post-traumatic stress disorder (PTSD), acute stress disorder (ASD), and depression frequently occur after experiencing a traumatic event, although the course can be variable [5].

PTSD and ASD are trauma and stressor-related psychiatric disorders that could occur after experiencing or witnessing events involving physical injury, death, or other threats to the physical integrity [4]. Re-experience of the traumatic event and avoidance of trauma-related stimuli are the main symptoms of trauma and stressor-related disorders [4]. Unlike PTSD and ASD, depression is a mental disorder that is not directly linked to a traumatic event. However, substantial depression prevalence rates have been reported among patients who experienced a traumatic event such as interpersonal violence $[6,7]$. A depressive episode is characterized by a constant depressed mood, loss of interest, or loss of pleasure [4].

A systematic review by Santiago et al. [5] reported that PTSD trajectories differ between patients exposed to intentional and non-intentional traumatic events. The PTSD prevalence among patients exposed to nonintentional traumatic events decreased in time, whereas the prevalence among patients exposed to intentional traumatic events increased. This might suggest that the PTSD trajectory of patients with violence-related injury differs from patients with non-intentional injury. However, Santiago et al. [5] also included studies on victims of terroristic attacks, war, and hostage situations in their systematic review. These participants did not necessarily sustained injury. It therefore remains unclear what the specific trajectories are for patients with violence related injury. Furthermore, little is known about the prevalence and trajectories of ASD and depression in this specific population.

In order to gain insight into the total health impact of injury following violence, the psychological consequences should be taken into account given the high prevalence rates of PTSD, ASD, and depression that have been reported post-injury $[5,8-10]$. This paper provides PTSD, ASD, and depression prevalence estimates among patients with violence related injury, which may inform our understanding of both prognosis and recovery for these patients.
An overview of prevalence rates provides insight into the public health treatment needs. Targeted interventions can be provided when the PTSD, ASD and depression trajectories of patients who sustained violence related injury are known. Therefore, we aim to (1) provide an overview of the published literature reporting the prevalence rates and trajectories of ASD, PTSD, and depression following violence related injury, and (2) to assess the quality of the studies included.

\section{Methods}

In order to identify studies reporting the prevalence rates of ASD, PTSD, and depression among patients who sustained violence related injury, a systematic literature review was conducted. The methods and reporting of this systematic review are in concordance with the PRISMA statement on reporting standards for systematic reviews [11]. The study protocol is registered in the PROSPERO international prospective register of systematic reviews (registration number CRD42016043167).

\section{Literature search}

Relevant studies were identified through systematic literature searches in the EMBASE, MEDLINE, Cochrane Central, PubMed, and PsycINFO databases. The search strategies were developed in consultation with a medical librarian. A detailed description of the search strategy can be found in the Additional file 1. Reference lists and citation indices of the included papers were inspected to identify additional relevant citations. We restricted searches to English-language papers, published in peer-reviewed journals before November 2017.

\section{Study selection}

Studies reporting the prevalence of PTSD, ASD, or depression after ED or hospital treated injury following interpersonal violence were included in this review. We defined the following inclusion and exclusion criteria:

\section{Participants}

Studies were included if the injury was intentionally caused by another person or persons, such as (sexual) assault or stabbing. Studies on violent incidents that not necessarily involve injury, such as hostage situations or witnessing terroristic attacks, were excluded. Studies on a mixed population, e.g. all trauma patients, were only included if they reported separate prevalence rates for injury caused by intentional violence (excluding self-harm). We only included studies on patients who have been treated at the ED or hospital in order to maintain comparability in terms of injury severity. We did not apply restrictions on countries or regions in which studies were conducted. Studies on adults, children, and adolescents were included. 


\section{Outcome}

We included studies in which the prevalence rates of PTSD, ASD or depression were reported directly or indirectly (i.e. by reporting the number of cases and the total number of patients) based on a validated questionnaire or diagnostic interview. We applied the case definitions and diagnostic thresholds as reported in the individual studies.

\section{Study design}

Prospective and retrospective cohort studies, longitudinal studies, cross-sectional studies, time series, and clinical trials were included. We excluded reviews, qualitative studies, case reports, editorials, and study protocols.

\section{Data extraction}

Titles and abstracts of all identified studies were screened for relevance by one reviewer ( $\mathrm{RO}, \mathrm{BO}$, or $\mathrm{JH})$. After initial selection, the remaining records were independently read in full-text by two reviewers ( $\mathrm{RO}$ and $\mathrm{BO}$ ) for the eligibility assessment. Discrepancies were discussed and resolved by consulting a third reviewer (JH). Two reviewers ( $\mathrm{RO}$ and $\mathrm{BO}$ ) extracted data on the study populations, study setting, injury details, prevalence rates, diagnostic instruments, and follow-up. If possible, we provided prevalence rates at different points in time. We used approximations when specific time points were not reported. For example, when 'within two weeks after ED admission' was reported as time indication, the midpoint (one week) was used. We reported gender-specific prevalence rates and measures of injury severity if provided.

\section{Quality assessment}

A quality assessment in terms of risk of bias was performed with the Quality in Prognosis Studies (QUIPS) tool [12], which was developed for assessing the risk of bias of prognostic studies. Although the current systematic review does not focus on prognostic studies, we used the QUIPS tool because it covers general quality criteria on risk of bias. We considered these general criteria as appropriate because of the variety of study designs included in our study. The following domains of the QUIPS were selected in order to assess the risk of bias: study participation, study attrition, outcome measurement, and statistical analysis. Two reviewers (RO and BO) independently used the QUIPS tool to assess the risk of bias. Each domain was scored as 'low risk', 'moderate risk' or 'high risk'. Any discrepancies in the domain scores were resolved via discussion until consensus was reached.

\section{Results}

Literature search

In total, the literature search yielded 3556 articles. After excluding 1537 duplicates, the titles and abstracts of 2019 articles were screened for relevance. The screening of titles and abstracts resulted in the exclusion of 1979 articles. Forty studies were left for full-text eligibility assessment, of which 24 were excluded for several main reasons: no prevalence reported, no violence related injury, no ED or hospital admission, literature review. Finally, sixteen studies were included in the systematic review. A flow chart of the study identification process is presented in Fig. 1.

\section{Study characteristics}

The majority of the studies were conducted in the United States $(n=10)$ [13-22] (Table 1). The remaining studies were conducted in the United Kingdom $(n=3)$ [23-25], Denmark $(n=1)$ [26], and Norway $(n=2)[27,28]$. Seven studies included patients aged eighteen years and older [14, 20-22, 26-28] and two studies included patients aged sixteen years and older [23, 25]. In two studies [13, 24], the age of the participants was not specified. The remaining five studies applied different age criteria (Table 1) $[15,19]$.

All studies included patients who presented to the ED, trauma center, or hospital with injury following intentional violence. Alarcon et al. [13] included patients with the ICD-9-CM injury codes 800-995, covering injury such as open wounds and fractures. Injury related to sexual assault was excluded in three studies $[14,15,19]$ and injury caused by domestic violence was excluded in four studies $[19,24,27,28]$. In four studies on children and adolescents, injury caused by child abuse was excluded [15, 16, 18, 19].

\section{Diagnostic instruments}

A full structured clinical interview was used as diagnostic instrument in four out of sixteen studies [15, 20, 22, 24]. All DSM IV or V diagnostic criteria for PTSD $(n=4)$ and depression $(n=1)$ were met in these studies (Table 2). The Child and Adolescents Trauma Survey for assessing PTSD symptoms was used as diagnostic instrument in two studies $[16,18]$. In both studies, patients were considered having PTSD when they scored 27 or higher. The Immediate Stress Response Checklist for ASD was used in the same studies $[16,18]$, although one of these studies did not report a cut-off score [18]. The diagnostic instruments used in the other studies were all different from each other. Twelve out of sixteen studies (75\%) used brief questionnaires based on self-report or screening measures to obtain probable diagnoses. Therefore, these studies may have included individuals who would not have met the diagnostic criteria for ASD, PTSD, or depression if a 


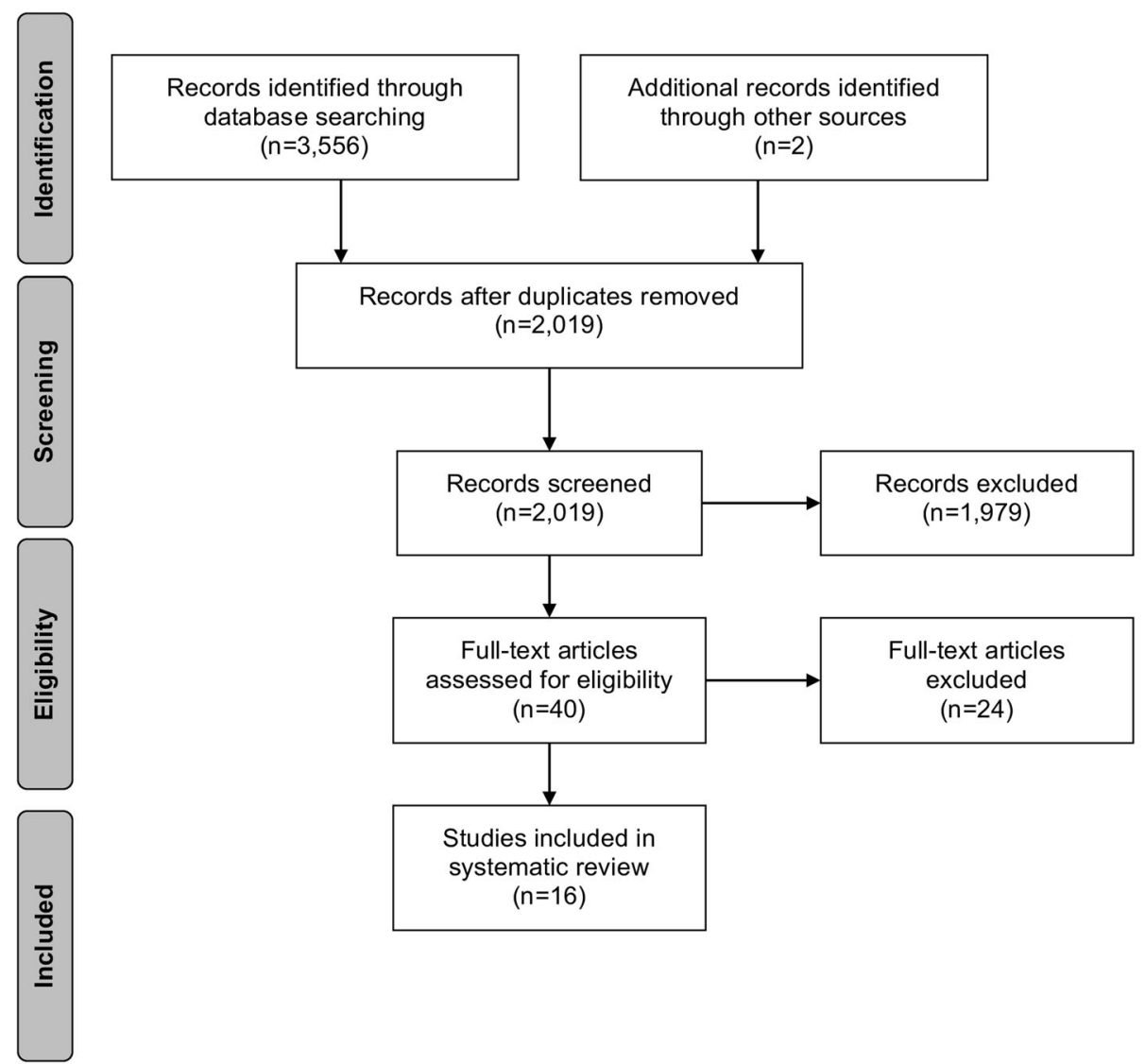

Fig. 1 Flow chart of the study identification process

full diagnostic interview would have been conducted. Brief questionnaires are mainly focused on symptoms whereas in a full diagnostic interview impairment is assessed as well.

\section{Prevalence rates}

The PTSD, ASD, and depression prevalence rates at different points in time are reported in Table 2. Fifteen studies reported the prevalence of PTSD following violence related injury [13, 15-28], five studies reported the prevalence of ASD [14, 16, 18, 24, 26], and five studies reported the prevalence of depression $[14,15,17,18,21]$. The PTSD prevalence at $1,3,6$, and 12 months post-injury ranged between $11.0-60.9 \%, 5.8-30.4 \%, 1.9-23.9 \%$, and $16.3-27.1 \%$ respectively. The following range of ASD prevalence rates were reported $<1$ week post-injury and $1-2$ weeks post-injury: $24.0-24.6 \%$ and $11.7-40.6 \%$. Four studies reported depression prevalence rates $<1$ month post-injury ranging between 3.0 and $35.3 \%$. Beyond one month post-injury, a prevalence rate of $16.8 \%$ was reported. Heterogeneity resulting from the use of different diagnostic instruments strongly limited the comparability of the reported prevalence rates of PTSD, ASD, and depression. In total, one study reported injury severity of the target population [26] and one study reported gender-specific prevalence rates [27] (Table 2).

\section{Quality assessment}

Of all 64 possible scoring options (four quality domains times sixteen studies), the reviewers disagreed on five scoring options resulting in a disagreement rate of $7.8 \%$. Two of the disagreements belonged to the study participation domain and three to the outcome measurement domain. Disagreements were resolved after discussion. Table 3 describes the risk of bias per domain (study participation, study attrition, outcome measurement, and statistical analysis) for all studies included. The study by Pailler et al. [18] was the only study with a low risk of bias on all four domains. The study attrition domain was mainly scored as high risk (83\%) because of low participation rates and/or poor descriptions of the patients lost to follow-up. One study scored 'low risk' in this domain [18]. The statistical analyses and the presentation of the results were adequate in all studies. Therefore, all studies scored 'low risk' on the statistical analyses domain. The outcome measurement domain was mainly scored as low risk (67\%). The majority had a low risk score for the study participation domain (67\%), but one study had a 
Table 1 Overview of the study characteristics reporting the prevalence of ASD, PTSD, or depression following violence related injury

\begin{tabular}{|c|c|c|c|c|c|}
\hline Authors, year, country, ref. & Study population & Setting details & $\begin{array}{l}\text { Violence and } \\
\text { injury details }\end{array}$ & Disorder & 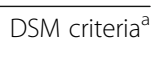 \\
\hline Alarcon et al., 2012, USA, [13] & $\begin{array}{l}\text { Injured patients treated at } \\
\text { the ED, age not specified }\end{array}$ & $\begin{array}{l}\text { Urban level I } \\
\text { trauma center }\end{array}$ & Assault & PTSD & No \\
\hline Bisson et al., 2010, UK, [23] & $\begin{array}{l}\text { Patients aged over } 16 \text { years, } \\
\text { treated at the ED following } \\
\text { physical assault }\end{array}$ & ED & Assault & PTSD & No \\
\hline Boccelari et al., 2007, USA, [14] & $\begin{array}{l}\text { Patients aged } 18 \text { years and } \\
\text { older who are victims of } \\
\text { violent crime treated at } \\
\text { the ED, with and without } \\
\text { hospitalization }\end{array}$ & Urban hospital & $\begin{array}{l}\text { All types of violence, } \\
\text { sexual assault excluded }\end{array}$ & Depression, ASD & No \\
\hline Cunningham et al., 2015, USA, [15] & $\begin{array}{l}\text { Patients aged between } \\
14 \text { and } 24 \text { years treated } \\
\text { at the ED following assault }\end{array}$ & $\begin{array}{l}\text { Urban public ED, high } \\
\text { crime rates in region }\end{array}$ & $\begin{array}{l}\text { Assault, sexual assault } \\
\text { and child abuse excluded }\end{array}$ & Depression, PTSD & Yes, DSM-IV \\
\hline Elklit et al., 2003, Denmark, [26] & $\begin{array}{l}\text { Patients aged } 18 \text { years and } \\
\text { older who are victims of } \\
\text { physical assault, treated at } \\
\text { the ED }\end{array}$ & ED & $\begin{array}{l}\text { Assault, mean Injury } \\
\text { Severity Score 1.47, } \\
\text { two-third of the sample } \\
\text { had head and face injuries }\end{array}$ & ASD, PTSD & No \\
\hline Fein et al., 2002, USA, [16] & $\begin{array}{l}\text { Patients aged between } 12 \\
\text { and } 24 \text { years treated at the } \\
\text { ED for intentional violence }\end{array}$ & Urban EDs & $\begin{array}{l}\text { Assault/fights, child abuse } \\
\text { and domestic violence } \\
\text { excluded }\end{array}$ & ASD, PTSD & No \\
\hline Hunt et al., 2016, USA, [20] & $\begin{array}{l}\text { Injured trauma survivors } \\
\text { aged } 18 \text { years and older, } \\
\text { admitted to trauma center, } \\
8.6 \% \text { of the patients were } \\
\text { victims of intentional } \\
\text { stabbing }\end{array}$ & $\begin{array}{l}\text { Two level I } \\
\text { trauma centers }\end{array}$ & Stabbing & PTSD & Yes, DSM-V \\
\hline Johansen et al., 2006, Norway, [27] & $\begin{array}{l}\text { Patients aged over } 18 \text {, treated } \\
\text { at the ED following assault }\end{array}$ & ED & $\begin{array}{l}\text { Assault, domestic } \\
\text { violence excluded }\end{array}$ & PTSD & No \\
\hline Johansen et al., 2007, Norway, [28] & $\begin{array}{l}\text { Patients aged } 18 \text { years and } \\
\text { older, treated at the ED } \\
\text { following physical assault }\end{array}$ & ED & $\begin{array}{l}\text { Assault, domestic } \\
\text { violence excluded }\end{array}$ & PTSD & No \\
\hline Kleim et al., 2007, UK, [24] & $\begin{array}{l}\text { Patients treated at the ED } \\
\text { following assault, mean } \\
\text { age } 35 \text { years }\end{array}$ & ED & $\begin{array}{l}\text { Assault, domestic } \\
\text { violence excluded }\end{array}$ & ASD, PTSD & $\begin{array}{l}\text { PTSD only, } \\
\text { DSM-IV }\end{array}$ \\
\hline McCart et al., 2005, USA, [17] & $\begin{array}{l}\text { Patients aged 9-18 years, } \\
\text { treated at the ED following } \\
\text { assault }\end{array}$ & ED & $\begin{array}{l}\text { Assault, with and } \\
\text { without weapons }\end{array}$ & Depression, PTSD & No \\
\hline Pailler et al., 2007, USA, [18] & $\begin{array}{l}\text { Patients aged between } 12 \\
\text { and } 17 \text {, treated at the ED } \\
\text { following a violence-related } \\
\text { event }\end{array}$ & ED & $\begin{array}{l}\text { Violent event, child } \\
\text { abuse excluded }\end{array}$ & $\begin{array}{l}\text { Depression, } \\
\text { ASD, PTSD }\end{array}$ & No \\
\hline Purtle et al., 2014, USA, [19] & $\begin{array}{l}\text { Patients aged between } \\
7 \text { and } 17 \text { years who } \\
\text { sustained intentional } \\
\text { interpersonal injury } \\
\text { treated at the ED }\end{array}$ & $\begin{array}{l}\text { Urban level I } \\
\text { trauma center }\end{array}$ & $\begin{array}{l}\text { Violent event, child abuse, } \\
\text { domestic violence, and } \\
\text { sexual assault excluded }\end{array}$ & PTSD & No \\
\hline Roy-Byrne et al., 2004, USA, [22] & $\begin{array}{l}\text { Patients aged } 18 \text { years } \\
\text { and older, admitted to } \\
\text { ED following sexual } \\
\text { or physical assault, not } \\
\text { requiring hospitalization }\end{array}$ & $\begin{array}{l}\text { Urban level I } \\
\text { trauma center }\end{array}$ & Sexual or physical assault & PTSD & Yes, DSM-IV \\
\hline Sullivan et al., 2017, USA, [21] & $\begin{array}{l}\text { Patients aged } 18 \text { years and } \\
\text { older, admitted to the trauma } \\
\text { service for at least } 24 \mathrm{~h} \\
\text { following aggravated assault }\end{array}$ & $\begin{array}{l}\text { Urban level I } \\
\text { trauma center }\end{array}$ & $\begin{array}{l}\text { Aggravated assault and } \\
\text { gunshot wounds }\end{array}$ & Depression, PTSD & No \\
\hline Walters et al., 2007, UK, [25] & $\begin{array}{l}\text { Patients aged over } 16 \text { years, } \\
\text { treated at the ED following } \\
\text { assault }\end{array}$ & ED & $\begin{array}{l}\text { Assault, no further } \\
\text { exclusion criteria }\end{array}$ & PTSD & No \\
\hline
\end{tabular}


Table 2 Overview of PTSD, ASD, and depression prevalence rates and diagnostic instruments

\begin{tabular}{|c|c|c|c|c|c|c|c|}
\hline \multirow[t]{2}{*}{ PTSD $(n=15)$} & \multirow[t]{2}{*}{ Instrument, cut-off } & \multirow[t]{2}{*}{ No./total no. } & \multicolumn{5}{|c|}{ Prevalence in \% $(95 \% \mathrm{Cl})$} \\
\hline & & & $<1$ month & 1 month & 3 months & 6 months & 12 months \\
\hline Alarcon et al. [13] & PCL-C, $\geq 35$ & $7 / 16$ & - & $43.7(11.4-76.2)$ & - & - & - \\
\hline Bisson et al. [23] & TSQ, $\geq 6$ & $338 / 3349$ & $59.1(52.8-65.4)$ & - & - & - & - \\
\hline Cunningham et al. [15] & MINI, DSM-IV criteria & $30 / 184$ & - & - & - & - & $16.3(10.5-22.1)$ \\
\hline Elklit et al. [26] & $\mathrm{HTQ}, \geq 3$ on all scales & $26 / 118$ & - & - & - & $22.0(13.5-30.5)$ & - \\
\hline Fein et al. [16] & CATS, $\geq 27$ & $4 / 96$ & - & - & $5.8(0.12-11.5)$ & - & - \\
\hline Hunt et al. [20] & CAPS, DSM-V criteria & $7 / 12$ & - & $58.3(15.1-100)$ & - & - & - \\
\hline Johansen et al. [27] & PTSS-10 $10^{a, b}$ & $46 / 138$ & - & $33.3(23.7-43.0)^{c}$ & - & - & - \\
\hline Johansen et al. [28] & PTSS-10 $10^{a, b}$ & 20/70, 17/70, 19-70 & - & $28.6(16.0-41.1)$ & $24.3(12.7-35.8)$ & - & $27.1(14.9-39.3)$ \\
\hline Kleim et al. [24] & SCID, DSM-IV criteria & $49 / 205$ & - & - & - & $23.9(17.2-30.6)$ & - \\
\hline McCart et al. [17] & TSCC, NR & $7 / 89$ & $7.1(1.85-12.4)$ & - & - & - & - \\
\hline Pailler et al. [18] & CATS, $\geq 27$ & $3 / 158$ & - & - & - & $1.9(3.8-12.7)$ & - \\
\hline Purtle et al. [19] & CTSQ, $\geq 5$ & $31 / 47$ & $66.0(42.7-89.2)$ & - & - & - & - \\
\hline Roy-Byrne et al. [22] & CAPS, DSM-V criteria & $14 / 23,7 / 23$ & - & $60.9(29.0-92.8)$ & $30.4(7.9-53.0)$ & - & - \\
\hline Sullivan et al. [21] & PC-PTSD, $\geq 3$ & $33 / 87$ & $37.9(25.0-50.9)$ & - & - & - & - \\
\hline Walters et al. [25] & DTS $^{d}$ & NR & - & $11(\mathrm{NR})$ & - & 7.7 (NR) & - \\
\hline \multirow[t]{2}{*}{$\operatorname{ASD}(N=5)$} & \multirow[t]{2}{*}{ Instrument, cut-off } & \multirow[t]{2}{*}{ No./total no. } & \multicolumn{5}{|c|}{ Prevalence in \% (95\% Cl) } \\
\hline & & & $<1$ week & 1 week & $>1$ week & & \\
\hline Boccelari et al. [14] & $\mathrm{ASDS}_{1}>36$ & $221 / 541$ & - & $40.9(35.5-46.2)$ & - & & \\
\hline Elklit et al. [26] & $\mathrm{HTQ}, \geq 2$ & $47 / 196$ & $24.0(17.1-30.8)$ & - & - & & \\
\hline Fein et al. [16] & ISRC & $17 / 69$ & $24.6(12.9-36.3)$ & - & - & & \\
\hline Kleim et al. [24] & ASDS, NR & $37 / 222$ & - & - & $16.7(11.3-22.0)$ & & \\
\hline Pailler et al. [18] & ISRC, NR & $46 / 394$ & - & $11.7(8.3-15.0)$ & - & & \\
\hline \multirow[t]{2}{*}{ Depression $(N=5)$} & \multirow[t]{2}{*}{ Instrument, cut-off } & \multirow[t]{2}{*}{ No./total no. } & \multicolumn{2}{|c|}{ Prevalence in \% (95\% Cl) } & & & \\
\hline & & & $<1$ month & $\geq 1$ month & & & \\
\hline Boccelari et al. [14] & $\mathrm{PHQ}, \mathrm{NR}$ & $191 / 541$ & $35.3(30.3-40.3)$ & - & & & \\
\hline Cunningham et al. [15] & MINI, DSM-IV criteria & $31 / 184$ & - & $16.8(10.9-22.8)$ & & & \\
\hline McCart et al. [17] & TSCC, NR & $5 / 89$ & $5.1(0.6-9.6)$ & - & & & \\
\hline Pailler et al. [18] & CDI-SF, $>65$ & $12 / 394$ & $3.0(1.3-4.8)$ & - & & & \\
\hline Sullivan et al. [21] & $\mathrm{PHQ}-8, \geq 10$ & $36 / 87$ & $41.4(27.9-54.9)$ & - & & & \\
\hline \multicolumn{8}{|c|}{ 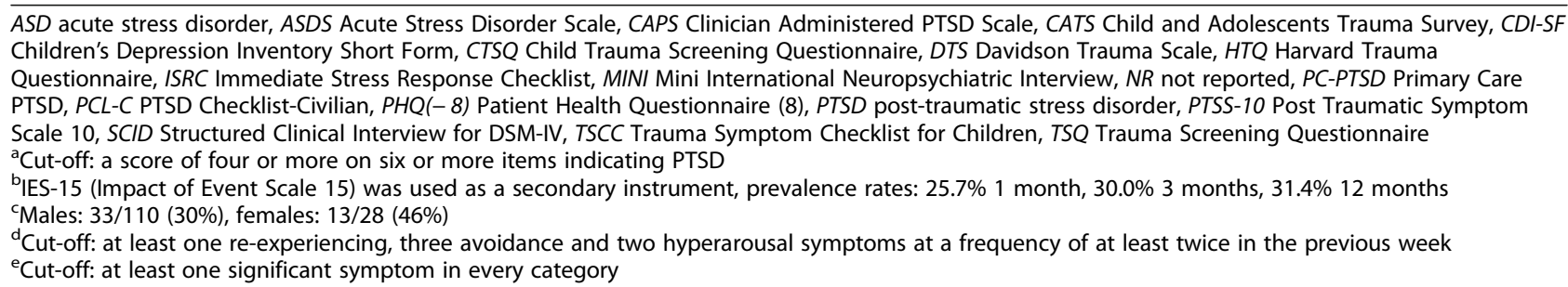 } \\
\hline
\end{tabular}

high risk of bias because the recruitment process, inclusion criteria, and baseline characteristics were not reported adequately [26].

\section{Discussion}

This systematic review provides an overview of the published literature reporting the prevalence rates and trajectories of PTSD, ASD, and depression following violence related injury treated at the ED or hospital. The quality of the included studies was assessed. We identified sixteen studies reporting the prevalence of ASD, PTSD, or depression. The reported prevalence rates were diverse across different follow-up points resulting in a wide range. The quality assessment indicated that almost all studies were susceptible to bias due to low response rates and loss to follow-up. 
Table 3 QUIPS risk of bias assessment

\begin{tabular}{|c|c|c|c|c|}
\hline Study & Study participation & Study attrition & Outcome measurement & $\begin{array}{l}\text { Statistical analysis } \\
\text { and presentation }\end{array}$ \\
\hline Alarcon et al. [13] & Low & High & Low & Low \\
\hline Bisson et al. [23] & Moderate & High & Low & NA \\
\hline Boccelari et al. [14] & Moderate & High & Moderate & Low \\
\hline Cunningham et al. [15] & Low & High & Moderate & Low \\
\hline Elklit et al. [26] & High & High & Low & Low \\
\hline Fein et al. [16] & Low & Moderate & Moderate & Low \\
\hline Hunt et al. [20] & Low & Moderate & Low & Low \\
\hline Johansen et al. [27] & Low & High & Moderate & Low \\
\hline Johansen et al. [28] & Low & High & Moderate & Low \\
\hline Kleim et al. [24] & Low & High & Low & Low \\
\hline McCart et al. [17] & Moderate & High & Low & Low \\
\hline Pailler et al. [18] & Low & Low & Low & Low \\
\hline Purtle et al. [19] & Low & High & Low & Low \\
\hline Roy-Byrne et al. [22] & Low & High & Low & Low \\
\hline Sullivan et al. [21] & Low & High & Low & Low \\
\hline Walters et al. [25] & Low & High & Low & Low \\
\hline
\end{tabular}

NA not applicable

In a previous meta-analysis on the prevalence of PTSD among trauma-exposed children and adolescents, an overall pooled prevalence rate of $15.9 \%$ was reported [29]. The pooled prevalence rate for victims of interpersonal violence was $25.2 \%$. The time of diagnosis was not specified, however. We found prevalence rates ranging from 1.9\% (3 months) to $66 \%(<1$ month) among children and adolescents. It is not warranted to aggregate these prevalence rates given the differences in the timing of the diagnosis and diagnostic instruments. White et al. [30] reported a PTSD prevalence of $14.3 \%$ among an adult sample that experienced a traumatic event. Again, this finding is difficult to compare with our results as the PTSD prevalence ranged from $7.7 \%$ (6 months) to $60.9 \%$ ( $<1$ month). Brewin et al. [31] reported an ASD prevalence estimate of $19 \%$ among adult violent crime victims who were not necessarily treated for injury. This prevalence rate is comparable with the ASD prevalence rates reported in four included studies (11.7-24.6\%), but one study reported a prevalence rate of $41 \%$ [14]. These findings suggest that ASD is highly prevalent in patients with violence related injury and that the prevalence is comparable to populations consisting of injured and non-injured violence victims.

Four studies reported PTSD prevalence rates before one month after the traumatic event [17, 19, 21, 23], which is not in accordance with the DSM (IV and V) criteria. It could be possible that these PTSD symptoms resulted from other traumatic events. Data on pre-existing PTSD, ASD, and depression among the study samples were not available, however. Consequently, it is unclear whether mental disorders were already present prior to the injury. This limitation is common in violence and injury research, but has to be taken into account when interpreting the results. It is also possible that people who already have PTSD, ASD or depression are more likely to be involved in interpersonal violence. It is known that PTSD is associated with more risk behavior [32] which could increase the likelihood of involvement in violence. Information regarding the diagnostic status before the injury is therefore valuable for interpreting the prevalence rates.

All studies were conducted in high-income countries, of which the vast majority in the United States. The findings of this review are therefore limited to these countries. Health care systems in high-income countries are relatively well established, which facilitates recognition, prevention, and treatment. It is therefore likely that the prevalence rates and trajectories of PTSD, ASD, and depression are different in middle and low-income countries.

\section{Strengths and limitations}

One of the strengths of our study is that standard methods for conducting and reporting systematic reviews were followed [11]. Furthermore, psychological, medical, and other relevant literature databases were searched exhaustively. Another strength is that we assessed the quality of the included studies. A limitation of our review is that the search was restricted to studies published in 
scientific peer-reviewed journals in English language. We did not consider dissertations, unpublished material or studies in non-English language, which could have biased our findings.

\section{Recommendations}

For future research, we recommend uniformity in diagnostic procedures. Structured diagnostic interviews by a clinician are preferred, but this is often not feasible. These interviews are time consuming and costly as they require involvement of trained professionals. Nevertheless, validated questionnaires can be used as an approximation. Our findings show that a large variety of questionnaires are available, however. Estimates of PTSD prevalence tend to vary according to the diagnostic criteria used, which underpins the need for uniformity in diagnostic procedures. These differences in diagnostic procedures could be reduced by establishing international guidelines on assessing mental health problems among trauma patients. Although international uniformity in diagnostic procedures would increase the comparability of PTSD, ASD and depression estimates, one should pay attention to ethnocultural differences. The validity of responses to measures may vary between populations, cultures, and countries [33]. Values and norms associated with culture guide perception and individual responses, including psychiatric symptoms [34]. Marshall et al. [35] investigated posttraumatic stress among a sample of Hispanic, non-Hispanic Caucasian, and African American survivors of physical injury. They found that the Hispanic group reported different symptoms and higher levels of overall posttraumatic distress. Such results raise questions regarding whether certain cultures truly experience higher levels of distress after experiencing a traumatic event, or whether cultural factors have an impact on the symptom manifestation only.

One of the sixteen included studies reported genderspecific prevalence rates. We recommend to report gender specific prevalence rates, since it is known that women are more likely to develop PTSD after trauma than men [29, 36]. Trajectories of PTSD, ASD, and depression can be better understood when distinguishing gender specific prevalence rates.

Prevalence rates should also be reported separately for injury types, such as sexual versus physical assault injuries and injuries caused by strangers versus family. The studies in the current review included patients with different injury types but prevalence rates were not reported separately. Identifying injury types that are associated with higher rates of PTSD, ASD, or depression may lead to earlier identification of high risk patients. Furthermore, ethnocultural differences in prevalence estimates should be considered in future studies. Cultural factors shape the subjective meaning of traumatic events, which in turn influences symptom expression [37].

Only few studies had follow-up measurements beyond one year after the violent incident. Previous studies suggest that the course of PTSD may vary over time. Prospective assessments are required to study the course of mental disorders following violence related injury treated at the ED or hospital. Since there are indications that the prevalence of PTSD among victims of intentional violence increases over time [5] it is relevant to know what the trajectories of PTSD and other mental disorders are for individuals who sustained injury following violence. For future research, extending the follow-up could contribute to better understanding of mental disorder trajectories following violence related injury.

\section{Conclusions}

Heterogeneity resulting from the use different diagnostic instruments limited the comparability of the ASD, PTSD, and depression prevalence rates. The reported prevalence rates should be interpreted carefully as almost all studies were susceptible to bias due to low response rates. Definitive or broad statements on the prevalence rates and trajectories are therefore not warranted. Study participation and loss to follow-up require more attention in future studies. Uniformity in diagnostic procedures is needed for future studies on mental disorders following violence related injury.

\section{Additional file}

Additional file 1: Search strategy. (DOCX $19 \mathrm{~kb})$

Abbreviations

ASD: acute stress disorder; DSM: Diagnostic and Statistical Manual of Mental Disorders; ED: emergency department; PTSD: post-traumatic stress disorder; QUIPS: Quality in Prognosis Studies

Acknowledgements

The authors thank W. Bramer for his contributions to the development of the literature search strategy and E. van Beeck for reviewing the manuscript.

Funding

The authors did not receive funding for this work.

Availability of data and materials

All relevant data are presented in the manuscript, tables, and figures. The search strategy for this systematic review is presented in Additional file 1. The review protocol can be obtained from PROSPERO (registration number CRD42016043167). Any other data are available from the corresponding author on request.

Authors' contributions

Study design: $\mathrm{RO}, \mathrm{SP}, \mathrm{JH}$. Eligibility assessment and data extraction: $\mathrm{RO}, \mathrm{BO}$, $J \mathrm{H}$. Writing the manuscript: RO. Editing and revising the manuscript: BO, SP, $J$. All authors read and approved the final manuscript.

Ethics approval and consent to participate Not applicable. 


\section{Consent for publication}

Not applicable.

\section{Competing interests}

The authors declare that they have no competing interests.

\section{Publisher's Note}

Springer Nature remains neutral with regard to jurisdictional claims in published maps and institutional affiliations.

Received: 27 December 2017 Accepted: 17 September 2018 Published online: 25 September 2018

\section{References}

1. World Health Organization: World Report on Violence and Health. 2002.

2. Lipsky S, Caetano R, Field CA, Bazargan S. Violence-related injury and intimate partner violence in an urban emergency department. J Trauma. 2004:57(2):352-9.

3. GBD 2016 Disease and Injury Incidence and Prevalence Collaborators. Global, regional, and national incidence, prevalence, and years lived with disability for 328 diseases and injuries for 195 countries, 1990-2016: a systematic analysis for the global burden of disease study 2016. Lancet. 2017:390(10100):1211-59.

4. American Psychiatric Association. Diagnostic and statistical manual of mental disorders. 5th ed. Washington: DC; 2013.

5. Santiago PN, Ursano RJ, Gray CL, Pynoos RS, Spiegel D, Lewis-Fernandez R, Friedman MJ, Fullerton CS. A systematic review of PTSD prevalence and trajectories in DSM-5 defined trauma exposed populations: intentional and non-intentional traumatic events. PLoS One. 2013;8(4):e59236.

6. Ellis A, Stores G, Mayou R. Psychological consequences of road traffic accidents in children. Eur Child Adolesc Psychiatry. 1998;7(2):61-8.

7. O'Donnell ML, Creamer M, Pattison P, Atkin C. Psychiatric morbidity following injury. Am J Psychiatry. 2004;161(3):507-14.

8. Haagsma JA, van Beeck EF, Toet H, Polinder S. Posttraumatic stress disorder following injury: trajectories and impact on health-related quality of life. Journal of Depression and Anxiety. 2013;2013.

9. Harvey AG, Bryant RA. Two-year prospective evaluation of the relationship between acute stress disorder and posttraumatic stress disorder following mild traumatic brain injury. Am J Psychiatry. 2000;157(4):626-8.

10. Koponen $S$, Taiminen $T$, Portin $R$, Himanen L, Isoniemi $H$, Heinonen $H$, Hinkka S, Tenovuo O. Axis I and II psychiatric disorders after traumatic brain injury: a 30-year follow-up study. Am J Psychiatry. 2002;159(8):1315-21.

11. Moher D, Liberati A, Tetzlaff J, Altman DG, Group P. Preferred reporting items for systematic reviews and meta-analyses: the PRISMA statement. Int $J$ Surg. 2010;8(5):336-41.

12. Hayden JA, van der Windt DA, Cartwright JL, Cote P, Bombardier C. Assessing bias in studies of prognostic factors. Ann Intern Med. 2013;158(4): 280-6.

13. Alarcon LH, Germain A, Clontz AS, Roach E, Nicholas DH, Zenati MS, Peitzman AB, Sperry JL. Predictors of acute posttraumatic stress disorder symptoms following civilian trauma: highest incidence and severity of symptoms after assault. J Trauma Acute Care Surg. 2012;72(3):629-35 discussion 635-627.

14. Boccellari A, Alvidrez J, Shumway M, Kelly V, Merrill G, Gelb M, Smart S, Okin $\mathrm{RL}$. Characteristics and psychosocial needs of victims of violent crime identified at a public-sector hospital: data from a large clinical trial. Gen Hosp Psychiatry. 2007;29(3):236-43.

15. Cunningham RM, Carter PM, Ranney M, Zimmerman MA, Blow FC, Booth BM, Goldstick J, Walton MA. Violent reinjury and mortality among youth seeking emergency department care for assault-related injury: a 2-year prospective cohort study. JAMA Pediatr. 2015;169(1):63-70.

16. Fein JA, Kassam-Adams N, Gavin M, Huang R, Blanchard D, Datner EM. Persistence of posttraumatic stress in violently injured youth seen in the emergency department. Arch Pediatr Adolesc Med. 2002;156(8):836-40.

17. McCart MR, Davies WH, Harris R, Wincek J, Calhoun AD, Melzer-Lange MD. Assessment of trauma symptoms among adolescent assault victims. J Adolesc Health. 2005;36(1):70 e77-13.

18. Pailler ME, Kassam-Adams N, Datner EM, Fein JA. Depression, acute stress and behavioral risk factors in violently injured adolescents. Gen Hosp Psychiatry. 2007;29(4):357-63.
19. Purtle J, Harris E, Compton R, Baccare R, Morris A, Dibartolo D, Campbell C, Vogel K, Schwartz N, Moront M. The psychological sequelae of violent injury in a pediatric intervention. J Pediatr Surg. 2014;49(11):1668-72.

20. Hunt JC, Sapp M, Walker C, Warren AM, Brasel K, deRoon-Cassini TA. Utility of the injured trauma survivor screen to predict PTSD and depression during hospital admission. J Trauma Acute Care Surg. 2017:82(1):93-101.

21. Sullivan E, Shelley J, Rainey E, Bennett M, Prajapati P, Powers MB, Foreman M, Warren AM. The association between posttraumatic stress symptoms, depression, and length of hospital stay following traumatic injury. Gen Hosp Psychiatry. 2017;46:49-54.

22. Roy-Byrne PP, Russo J, Michelson E, Zatzick D, Pitman RK, Berliner L. Risk factors and outcome in ambulatory assault victims presenting to the acute emergency department setting: implications for secondary prevention studies in PTSD. Depress Anxiety. 2004;19(2):77-84.

23. Bisson Jl, Weltch R, Maddern S, Shepherd JP. Implementing a screening programme for post-traumatic stress disorder following violent crime. Eur J Psychotraumatol. 2010;1.

24. Kleim B, Ehlers A, Glucksman E. Early predictors of chronic post-traumatic stress disorder in assault survivors. Psychol Med. 2007:37(10):1457-67.

25. Walters JT, Bisson JI, Shepherd JP. Predicting post-traumatic stress disorder: validation of the trauma screening questionnaire in victims of assault. Psychol Med. 2007:37(1):143-50.

26. Elklit A, Brink O. Acute stress disorder as a predictor of post-traumatic stress disorder in physical assault victims. J Interpers Violence. 2004;19(6):709-26.

27. Johansen VA, Wahl AK, Eilertsen DE, Hanestad BR, Weisaeth L. Acute psychological reactions in assault victims of non-domestic violence: peritraumatic dissociation, post-traumatic stress disorder, anxiety and depression. Nord J Psychiatry. 2006;60(6):452-62.

28. Johansen VA, Wahl AK, Eilertsen DE, Weisaeth L. Prevalence and predictors of post-traumatic stress disorder (PTSD) in physically injured victims of nondomestic violence. A longitudinal study. Soc Psychiatry Psychiatr Epidemiol. 2007:42(7):583-93.

29. Alisic E, Zalta AK, van Wesel F, Larsen SE, Hafstad GS, Hassanpour K, Smid $\mathrm{GE}$. Rates of post-traumatic stress disorder in trauma-exposed children and adolescents: meta-analysis. Br J Psychiatry. 2014;204:335-40.

30. White J, Pearce J, Morrison S, Dunstan F, Bisson Jl, Fone DL. Risk of posttraumatic stress disorder following traumatic events in a community sample. Epidemiol Psychiatr Sci. 2015;24(3):249-57.

31. Brewin CR, Andrews B, Rose S, Kirk M. Acute stress disorder and posttraumatic stress disorder in victims of violent crime. Am J Psychiatry. 1999;156(3):360-6.

32. Danielson CK, Amstadter AB, Dangelmaier RE, Resnick HS, Saunders BE, Kilpatrick DG. Trauma-related risk factors for substance abuse among male versus female young adults. Addict Behav. 2009;34(4):395-9.

33. Hinton DE, Lewis-Fernandez R. The cross-cultural validity of posttraumatic stress disorder: implications for DSM-5. Depress Anxiety. 2011;28(9):783-801.

34. Schubert CC, Punamaki RL. Mental health among torture survivors: cultural background, refugee status and gender. Nord J Psychiatry. 2011;65(3):175-82

35. Marshall GN, Schell TL, Miles JN. Ethnic differences in posttraumatic distress: Hispanics' symptoms differ in kind and degree. J Consult Clin Psychol. 2009; 77(6):1169-78.

36. de Vries GJ, Olff M. The lifetime prevalence of traumatic events and posttraumatic stress disorder in the Netherlands. J Trauma Stress. 2009;22(4): 259-67.

37. Stephens KA, Sue S, Roy-Byrne P, Unutzer J, Wang J, Rivara FP, Jurkovich GJ, Zatzick DF. Ethnoracial variations in acute PTSD symptoms among hospitalized survivors of traumatic injury. J Trauma Stress. 2010;23(3):384-92.

Ready to submit your research? Choose BMC and benefit from:

- fast, convenient online submission

- thorough peer review by experienced researchers in your field

- rapid publication on acceptance

- support for research data, including large and complex data types

- gold Open Access which fosters wider collaboration and increased citations

- maximum visibility for your research: over $100 \mathrm{M}$ website views per year

At $\mathrm{BMC}$, research is always in progress.

Learn more biomedcentral.com/submissions 